\title{
¿Y dónde está la gracia? El humor en el aula de ELE
}

\author{
ESTHER LINARES BERNABÉU \\ Universidad de Alicante \\ Esther.Linares@ua.es
}

Resumen: El presente trabajo muestra el fenómeno pragmático del humor como un instrumento idóneo para suscitar la reflexión sobre el uso y funciones del lenguaje en los estudiantes de ELE. Una vez expuestas las referencias al humor verbal y a la ironía por parte del Marco Común Europeo de Referencia y el Plan Curricular del Instituto Cervantes, ofreceremos una propuesta didáctica cuyo objetivo es la activación y desarrollo de la competencia comunicativa. Muestras humorísticas como el monólogo pueden contribuir a mejorar las destrezas lingüísticas y pragmáticas en ELE desde niveles iniciales.

Palabras clave: Humor, Competencia metapragmática, ELE, Propuesta didáctica.

\begin{abstract}
This paper shows the pragmatic phenomenon, humour, as an ideal tool to promote students' awareness of the uses and functions of the language. After having presented verbal humour and irony within the Common European Framework of Reference and the Curricular Plan of the Instituto Cervantes, we will offer a didactic proposal focused on the activation and development of the communicative competence. Humorous samples such as Stand-Up may enhance linguistic and pragmatic skills in Spanish as FL from novice levels.
\end{abstract}

Key words: Humour, Metapragmatic competence, Spanish as a Foreign Language, Didactic Proposal. 


\section{Introducción}

El humor comporta numerosos beneficios sociales y psicológicos para los estudiantes de segundas lenguas. Se trata de un fenómeno pragmático cuyo componente afectivo contribuye a generar un clima relajado de aprendizaje y favorece la creación de lazos de compañerismo. Asimismo, diversos estudios demuestran que el uso del humor acrecienta el interés por la materia, así como la mejor retención de los conocimientos (cfr. Schmitz, 2002).

Por otro lado, estamos convencidos de que su inclusión en las sesiones didácticas podría servir para evaluar el dominio de lengua de los estudiantes, ya que «its successful comprehension often requires a broad base of linguistic, pragmatic, sociolinguistic, and cultural knowledge»(Cook, 2000: 204). De hecho, la competencia humorística está directamente relacionada con la competencia comunicativa ${ }^{1}$, ya que ser competente a nivel humorístico implica un conocimiento de los elementos lingüísticos (competencia lingüística), la capacidad de estructurar y emplear un discurso adecuado al contexto (competencia pragmática) y la adquisición de determinadas destrezas para abordar la dimensión social del uso de la lengua (competencia sociolingüística).

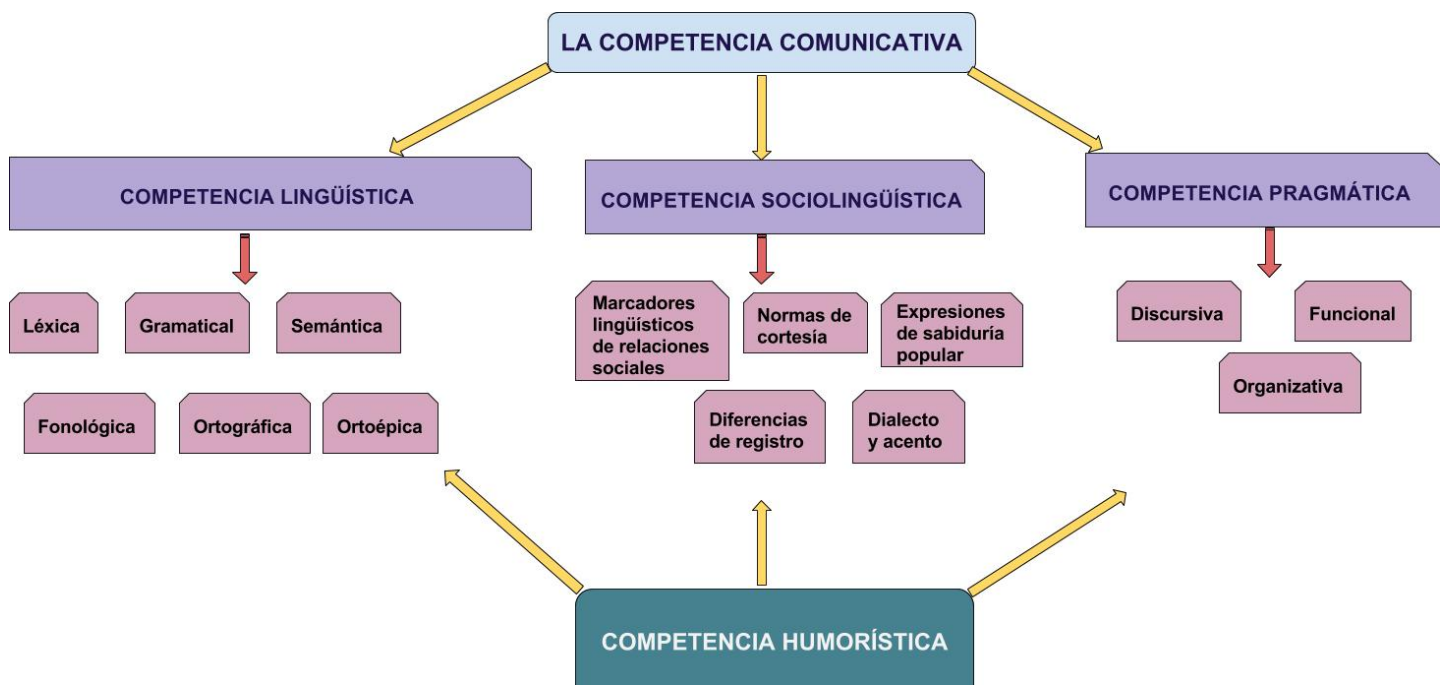

Figura 1 La competencia humorística en relación con la competencia comunicativa

Atributos del lenguaje como la polisemia, la homonimia, las unidades fraseológicas o las locuciones aparecen continuamente en el humor verbal, por lo que el uso de este en el aula promueve no solo un ambiente de aprendizaje distendido, sino que también favorece la retención de conocimientos y el desarrollo de la competencia comunicativa en la lengua meta. En esta línea, Bell, (2009: 241) defiende que el humor es un instrumento excelente "for students to learn the vocabulary, syntax, semantics, and discourse conventions of the target language, as well as to gain insight into the culture of those who speak that language». En resumen, no cabe duda de que experimentar con el humor en el aula nos permite trabajar conceptos lingüísticos que podrían ser en principio tediosos, y examinar las destrezas comunicativas de nuestro alumnado.

\footnotetext{
${ }^{1}$ Nuestro esquema difiere de la idea defendida por Vega (1990), quien atendiendo a los componentes de la competencia comunicativa propuestos por Canale (1983), concibe el humor como una quinta competencia al nivel de la estratégica, discursiva, lingüística y sociolingüística.
} 
Por ello, el objetivo principal de este trabajo será demostrar que es posible introducir el humor dentro de los contenidos programados para el curso de lengua, eligiendo siempre muestras humorísticas que no hieran las sensibilidades de los alumnos ni del centro educativo. Los estudiantes extranjeros a menudo expresan el deseo de entender mejor el humor y el aula nos proporciona el espacio idóneo para la experimentación, sin que estos se sientan avergonzados por no entenderlo (Bell, 2011). De hecho, aprender cualquier competencia o conocimiento nuevo requiere un proceso de prueba y error. Así que, ¿por qué no fomentar la competencia humorística desde la clase de ELE?

\section{Estado de la cuestión}

Tal y como queda reflejado en el trabajo de Gironzetti y Koike (2016), la sociopragmática sigue sin recibir la suficiente atención en la enseñanza de ELE. A pesar de que el humor verbal como hecho pragmático tiene un espacio reservado dentro del Marco Común Europeo de Referencia y el Plan Curricular del Instituto Cervantes (MCER y del PCIC, en adelante), este no es lo suficientemente notorio. Por un lado, el $M C E R^{2}$ dedica un apartado a las competencias pragmáticas de la lengua e inserta el uso del humor como un componente que se debe valorar en la adecuación sociolingüística del nivel avanzado C1. Por el otro lado, el PCIC refleja dentro del apartado de Tácticas y estrategias pragmáticas una serie de intenciones del hablante que pueden guiarnos a la hora de diseñar actividades con enfoque comunicativo y humorístico. Además, en el subapartado de Construcción e interpretación del discurso se alude a una serie de indicadores lingüísticos (morfológicos, léxicos y fónicos) que facilitan el reconocimiento e interpretación de enunciados figurados como son el humor o la ironía (PCIC, 2006: 261-265). Sin embargo, como señala Ruiz Gurillo (2008), el PCIC olvida incluir el repertorio de elementos no lingüísticos, es decir, las marcas tipográficas, acústico-melódicas, y kinésicas, esenciales para inferir el humor. Asimismo, en el apartado de Géneros discursivos ${ }^{3}$, se nos insta a enseñar aspectos referidos al humor en el aula a partir del nivel B2, acotando dicha enseñanza a chistes sin implicaciones socioculturales.

\section{Metodología}

Siguiendo lo que dicta el $M C E R$, nuestra sesión didáctica tendrá un enfoque orientado a la acción, en el que el estudiante será el foco de atención y el docente actuará como facilitador del conocimiento. Es bien sabido que uno aprende y recuerda mejor aquello que hace por él mismo.

\footnotetext{
${ }^{2}$ En la rúbrica para la evaluación de competencias, observamos el epígrafe de adecuación sociolingüística para el que el alumno en nivel avanzando "Utiliza la lengua con flexibilidad y eficacia para fines sociales, incluyendo los usos emocional, alusivo y humorístico.” (MCER, 2002:119)

3 Para mayor detalle, consúltese $<$ http://cvc.cervantes.es/ensenanza/biblioteca_ele/plan_curricular/niveles/07_generos_discursivos_invent ario_b1-b2.htm>
} 
Además, estimamos oportuno seguir la metodología del aprendizaje basado por tareas con un proyecto final, para así lograr aumentar la motivación de los estudiantes al verle un sentido práctico al aprendizaje. El conjunto de tareas culminará con la producción del humor por parte del alumnado a través de la creación de un pequeño monólogo. Ello se realizará en grupos de 3 o 4 personas con tal de promover el aprendizaje cooperativo y la creación de lazos de compañerismo entre todos ellos. De hecho, producir humor en una lengua extranjera nunca es una tarea fácil, por lo que la aportación de ideas entre los miembros y la revisión en grupo facilitará la tarea.

Asimismo, buscamos promover la reflexión sobre los usos y funciones de la lengua, además de integrar aspectos socioculturales. Esta reflexión quedará integrada en nuestra sesión por medio del Aprendizaje Basado en el Pensamiento (Thinking Based Learning) (cfr. Swartz et al., 2007). En definitiva, nuestro propósito será activar las habilidades metapragmáticas del alumnado y promover el desarrollo de la competencia sociolingüística e intercultural.

Todo ello quedará a su vez enmarcado dentro de un enfoque comunicativo, ya que, como bien se insiste desde el $M C E R$, la enseñanza de lenguas ha de tener presente la comunicación e interacción como núcleos del aprendizaje. Por ello, una enseñanza efectiva y significativa para el estudiante, pasa por enfocar nuestro contenido desde una perspectiva pragmática. Así, el humor, como hecho pragmático, colaborará en nuestro propósito de presentar muestras de lenguaje real que contribuyan al desarrollo de las habilidades sociolingüísticas e interculturales de nuestros estudiantes.

\section{Propuesta de sesión didáctica}

A continuación, presentamos nuestra propuesta didáctica para trabajar el monólogo como género humorístico. En concreto, las actividades están pensadas para ser trabajadas con jóvenes, estudiantes de ELE, en niveles avanzados. El material audiovisual seleccionado trata sobre el juego para móvil Pokémon Go, por lo que serán sobre todo los adolescentes los que encuentren más atractiva esta secuenciación didáctica

\subsection{Ficha para la sesión didáctica}

\begin{tabular}{|l|l|}
\hline Nombre de la actividad & ¿Y dónde está la gracia? \\
\hline Autor & Esther Linares Bernabéu \\
\hline Nivel & $\mathrm{C} 1$ \\
\hline Destinatarios & Adolescentes \\
\hline Duración & Dos sesiones de 50 minutos \\
\hline Objetivos & $\begin{array}{l}\text { Mejorar la competencia pragmático-discursiva de los } \\
\text { estudiantes. } \\
\text { Reflexionar sobre el funcionamiento del humor y la ironía por } \\
\text { medio del monólogo. } \\
\text { Despertar la conciencia metapragmática. }\end{array}$ \\
\hline
\end{tabular}




\begin{tabular}{|c|c|}
\hline & $\begin{array}{l}\text { Activar sus conocimientos culturales sobre los } \\
\text { comportamientos propios de los españoles para generar } \\
\text { interacción. } \\
\text { Comprender y utilizar con adecuación algunas expresiones del } \\
\text { habla coloquial. } \\
\text { Deducir los valores comunicativos del humor. }\end{array}$ \\
\hline Competencias lingüísticas & $\begin{array}{l}\text { Competencia léxica, semántica, ortoépica y pragmático- } \\
\text { discursiva. }\end{array}$ \\
\hline Competencia intercultural & $\begin{array}{l}\text { Transferir al español los conocimientos y estrategias } \\
\text { comunicativas adquiridas en otras lenguas. } \\
\text { Relacionar la cultura de origen con la cultura hispana y } \\
\text { comparar así sus hábitos y aficiones con los de los adolescentes } \\
\text { españoles de hoy en día. }\end{array}$ \\
\hline Contenidos concretos & $\begin{array}{l}\text { Implementación del estilo directo e indirecto, de figuras } \\
\text { retóricas como el símil, la metáfora y la antonimia. } \\
\text { Presentación de locuciones y unidades fraseológicas. } \\
\text { Reflexión sobre contenidos funcionales (señales de asertividad } \\
\text { y marcadores de control de contacto). }\end{array}$ \\
\hline Destrezas & EE, EO CAU, IO, IE, $\mathrm{CE}^{4}$ \\
\hline Dinámica & Individual, por parejas, grupos y toda la clase. \\
\hline Materiales & $\begin{array}{l}\text { Fichas, cartulinas, ordenador con conexión a internet, proyector } \\
\text { vídeo }\end{array}$ \\
\hline Evaluación & $\begin{array}{l}\text { Rúbrica evaluativa de las competencias y cuestionario de } \\
\text { autoevaluación }\end{array}$ \\
\hline Orientaciones para el profesor & $\begin{array}{l}\text { Si los alumnos no son capaces a priori de reconocer el humor a } \\
\text { través de los indicadores lingüísticos, el docente aludirá a las } \\
\text { marcas acústico-melódicas y kinésicas del monologuista con tal } \\
\text { de facilitar la resolución de la incongruencia. } \\
\text { Los ejercicios están elaborados de manera sucesiva, aunque } \\
\text { pueden variar el orden según considere el profesor. } \\
\text { El profesor ejerce como dinamizador y posibilitador del proceso } \\
\text { de aprendizaje }\end{array}$ \\
\hline
\end{tabular}

Figura 2. Ficha para a sesión didáctica

\subsection{Secuenciación}

En la siguiente secuenciación, se propone un elenco de actividades lúdicas y creativas para la inclusión del humor en el aula ELE, a través del monólogo humorístico. Nuestro

\footnotetext{
${ }^{4}$ Expresión escrita (EE), expresión oral (EO), comprensión audiovisual (CAU), interacción oral (IO), interacción escrita (IE), comprensión escrita (CE).
} 
ejemplo ${ }^{5}$ se extrajo del programa Late Motiv que presenta Andreu Buenafuente en Movistar TV. Como hemos comentado previamente, el monólogo trata un tema actual con el que la mayoría de los adolescentes se sienten identificados, el juego de móvil Pokémon GO.

La sesión didáctica se compone de siete tareas más el proyecto final; estas actividades están diseñadas para ser desarrolladas durante dos clases de 50 minutos. No obstante, estas pueden alargarse o acortarse según la dinámica del aula.

\section{Actividad 1 (10 MINUTOS) IO \& IE}

- Procedimiento: Primera fase de interacción grupal para poner en contexto a nuestros estudiantes.

- Tarea de previsionado en la que se introduce el monólogo como género humorístico a través de una lluvia de ideas sobre sus características.

- A continuación, presentamos una foto del humorista Andreu Buenafuente, con tal de ver si lo reconocen. En caso contrario, se realizará una breve descripción sobre él. Se trata de un ejercicio de calentamiento para comprobar los conocimientos socioculturales de nuestros estudiantes.

- Por último, invitamos a que, en parejas, piensen desde dónde va a realizar Buenafuente su monólogo y a quién va a ir dirigido.

\section{Actividad 2 (20 MINUTOS) CAU, CA, IO, EO}

- Procedimiento: Fase individual de comprensión audiovisual y posterior interacción con todo el grupo.

- En primer lugar, presentaremos un glosario con términos y expresiones posiblemente desconocidas para los alumnos, con tal de que la audición resulte más sencilla.

- Seguidamente pasamos al primer visionado del monólogo, en el que se busca obtener una comprensión global del mismo.

- Con tal de saber si han entendido el contenido, realizaremos un ejercicio de verdadero o falso de forma oral con toda la clase. Usaremos una cartulina roja si el enunciado que el/la docente diga es falso y verde si es correcto.

- Concluiremos esta segunda tarea con un pequeño coloquio sobre la afición a este juego móvil por parte de los propios estudiantes y la repercusión que ha tenido es sus países de origen.

\section{Actividad 3 (20 minutos) CAU, CE Y EE}

- Procedimiento: Realizaremos un ejercicio de reflexión sobre el valor comunicativo de diferentes figuras retóricas y fenómenos del lenguaje como la metáfora o la polisemia. Lo importante no es tanto que conozcan la definición de

\footnotetext{
${ }^{5}$ Enlace al material audiovisual: https:/www.youtube.com/watch? $\mathrm{v}=\mathrm{GJI} 1 \mathrm{JQ} 4$ fy0k\&t=45s
} 
cada uno de los indicadores lingüísticos, sino que distingan su uso figurado dentro de un contexto humorístico y que observen cómo colaboran en la inversión del Principio de informatividad.

- La segunda vez que proyectemos el vídeo, pediremos una escucha atenta con el objetivo de que fijar su atención en el uso de figuras retóricas como la polisemia, el símil, la metáfora, etc.

- A continuación, se pasará a explicar el funcionamiento de cada una de las figuras y el uso de estas en el humor. Usando los mismos ejemplos de la actividad anterior, deberán clasificarlos según la categoría.

- Trabajo individual y toda la clase.

\section{Actividad 4 (15 minutos) IO, EO Y CA}

- Procedimiento: El componente lúdico será el que guíe esta cuarta actividad. El objetivo de esta tarea es que las y los alumnos aprendan el significado de determinadas locuciones y unidades fraseológicas, para después inferir la desautomatización que se ha producido sobre ellas en este monólogo.

- Dividiremos la clase en dos grupos. El grupo A tendrá el significado del refrán "más vale pájaro en mano que ciento volando" y el grupo B conocerá el significado de la locución "echarle los trastos a alguien". Deberán aportar al equipo contrario la definición correcta junto con dos definiciones más inventadas.

- Ganará el equipo que suene más convincente y logre que el rival no acierte el significado correcto.

- Por último, con la transcripción delante, deberán buscar la desautomatización que se ha hecho de los mismos. Se les invitará a intentar crear sus propias desautomatizaciones del refrán.

\section{Actividad 5 (15 minutos) CE Y IO}

- Procedimiento: Se hará referencia al papel de la audiencia en el monólogo. Trataremos de reflejar las alusiones a ésta en el monólogo.

- Por tercera y última vez, los estudiantes verán el monólogo. Se trata de una audición selectiva en la que el alumnado únicamente debe fijar su atención en las señales fáticas $\mathbf{y}$ en los marcadores de control de contacto con tal de hacerles reflexionar sobre el registro oral que se emplea. En el ejercicio, tendrán que unir estos elementos con la frase que precede.

- El profesor o profesora deberá parar la atención de los estudiantes en las marcas extralingüísticas como los gestos del monologuista o la entonación, para así facilitar la distinción.

- Para acabar, realizaremos una lluvia de ideas sobre las funciones del humor y finalmente, se les entregará una infografía con las funciones principales. Este último ejercicio se enfocará desde la metodología basada en el pensamiento. 


\section{Actividad 6 (20 minutos) EO Y IO}

- Procedimiento: Concluiremos esta sesión didáctica con un coloquio sobre las diferencias en el humor en las diferentes lenguas y países.

- El alumnado necesitará conocer estrategias sobre cómo ganar tiempo para pensar (usando marcadores como: $\mathrm{mmm}$, eeeh, déjame ver...), cómo cambiar de tema (a propósito, fijate, por otro lado...), cómo parecer interesados en la intervención del hablante (apoyos), etc. antes de interactuar.

- La / el docente actuará como moderador de la charla, deberá fijarse no sólo en la entonación o la corrección lingüística de las intervenciones, sino también en cualquier estereotipo o prejuicio al que pudiera hacerse referencia con tal de desmitificarlo.

- Se trata de una actividad distendida en la que intentaremos desarrollar la fluidez lingüística del estudiante con la que pondremos el broche final a nuestro proyecto sobre el humor en español.

\section{Conclusión}

En resumen, el humor ha de ser un aliado en la labor docente, ya que un fragmento humorístico puede, en ocasiones, ser más significativo para el alumno/a que cualquier explicación teórica proporcionada por el manual de lengua. Ahora bien, si no empleamos con corrección esta herramienta, el humor puede resultar un distractor en el aula y arruinar toda nuestra sesión didáctica (cfr. Pomerantz \& Bell, 2011). Introducir material humorístico en las lecciones debe ser una acción meditada y estructurada que colabore en el desarrollo de la competencia comunicativa de nuestros estudiantes. Es necesario que, antes de implementar el humor en el aula, el profesorado conozca cuáles son los intereses y conocimientos culturales de sus estudiantes. Además, la selección del material humorístico debe también potenciar el desarrollo de la competencia intercultural, por lo que conviene alejarnos de los estereotipos culturales con tal de evitar frustraciones y sensibilidades heridas en el aula, (cfr. Deniere, 1995: 288).

En definitiva, el humor puede ser un buen recurso para que el docente consiga su propósito de acercar al estudiante al mundo real y pueda introducir en el aula aspectos tan importantes como la pragmática, la interculturalidad o las diferentes variedades de la lengua. Tal vez deberíamos desmontar el refrán de "la letra con sangre entra" y crear así su desautomatización "la letra con risa entra", ya que estamos convencidos de que un ambiente de aprendizaje animado y alegre favorece la retención de los conocimientos y aumenta la capacidad memorística. Así pues, teniendo en cuenta el valor de las emociones en el aprendizaje (cfr. Mora, 2013) y la relación intrínseca del humor con las emociones, concretamente con la alegría (cfr. Martin, 2007), nos preguntamos: ¿por qué no alegrar la vida de nuestros alumnos? 


\section{Bibliografía}

BELL, N. (2009). «Learning about and through humor in the second language classroom». Language Teaching Research, 13(3), 241-258.

BELL, N. (2011). «Humor scholarship and TESOL: Applying findings and establishing a research agenda». TESOL Quarterly, 45(1), 134-159.

Buenafuente, A. (Movistar+) (2016). «Monólogo Pokemon Go». Late Motiv. Recuperado el 24/10/2016 de https://www.youtube.com/watch?v=GJIJQ4fy0k\&t=45s

Canale, M. (1983). «De la competencia comunicativa a la pedagogía comunicativa del lenguaje». En Llobera et al., Competencia comunicativa. Documentos básicos en la enseñanza de lenguas extranjeras. Madrid: Edelsa, pp. 63-83.

Cook, G. (2000). Language play, language learning. Oxford: Oxford University Press.

CONSEJO DE EuROPA (2002). Marco común europeo de referencia para las lenguas: aprendizaje, enseñanza, evaluación. Madrid: Ministerio de Educación, Cultura y Deporte. Secretaría General Técnica del MECD-Subdireción General de Informaciones y Publicaciones y Grupo ANAYA.

Corpas, J. (2004). «La utilización del vídeo en el aula de E/LE. El componente cultural». RedELE $\mathrm{n}^{\circ} 1$. Recuperado de: http://www.mec.es/redele/revista1/corpas.shtml DeneIRE, M. (1995). «Humor and foreign language teaching». Humor: International Journal of Humor Research, 8(3), 285-298.

Instituto Cervantes (2006). Plan Curricular del Instituto Cervantes. Madrid: Instituto Cervantes.

GironzetTi, E. \& Koike, L (2016). «Bridging the gap in Spanish instructional pragmatics: from theory to practice/Acortando distancias en la enseñanza de la pragmática del español: de la teoría a la práctica», Journal of Spanish Language Teaching, 3:2, 89-98. DOI: 10.1080/23247797.2016.1251781

GRIALE (2011). ¿Estás de broma? 20 actividades para practicar la ironía en clase de ELE. Madrid: Edinumen.

Martín Peris, E., Cortés, M., \& Lopez, C. (2008). Diccionario de términos clave de ELE del CVC. Madrid: SGEL. Recuperado de:

http://cvc.cervantes.es/ensenanza/biblioteca_ele/diccio_ele/indice.htm

Martin, R.A. (2007). The Psychology of Humor: An Integrative Approach. Burlington: Elsevier Academic Press.

Pomerantz, A., \& Bell, N. (2011). «Humor as safe house in the foreign language classroom». The Modern Language Journal, 95(s1), 148-161.

Real ACAdemia Española (2014). Diccionario de la lengua española, 23 a edición, Madrid: Espasa Libros. 
Ruiz GuRILlo, L. (2008): «El lugar de la ironía en la clase de español como lengua extranjera. Más allá del Marco y del Plan Curricular». RedELE, 14. Recuperado de: http://rua.ua.es/dspace/bitstream/10045/13076/1/Leonor_Ruiz_Lugar_ironia.pdf.

Ruiz Gurillo, L. (2013): «El monólogo humorístico como tipo de discurso. El dinamismo de los rasgos primarios». Cuadernos AISPI, 189-212.

Ruiz Gurillo, L. (2013): «Eva Hache y El Club de la Comedia: del guión monológico al registro dialógico». Revista Onomázein, 28, 148-161

RuIz GuRILlo, L. (2014): "Infiriendo el humor. Un modelo de análisis para el español», Revista CLAC (Círculo de Lingüística Aplicada a la Comunicación), 59, 148162. Recuperado de: http://pendientedemigracion.ucm.es/info/circulo/no59/rgurillo.pdf

Schmitz, J.R. (2002). «Humor as a pedagogical tool in foreign language and translation courses». Humor: International Journal of Humor Research, 15(1), 89-113.

Swartz, R., Costa, A., Beyer, B., Reagan, R., \& Kallick, B. (2007). Thinking based learning. Norwood, MA: Christopher-Gordon.

VegA, G. (1990). «Humor competence: The fifth component». Trabajo presentado en el Annual Meeting of Teachers of English to Speakers of Other Languages, San Francisco, CA. 
ANEXO: Fichas para los estudiantes

\section{ACTIVIDAD 1}

- ¿Qué es un monólogo? ¿Cuáles son sus principales características? Comparte tus ideas con el resto del grupo (máximo 4 miembros/as).
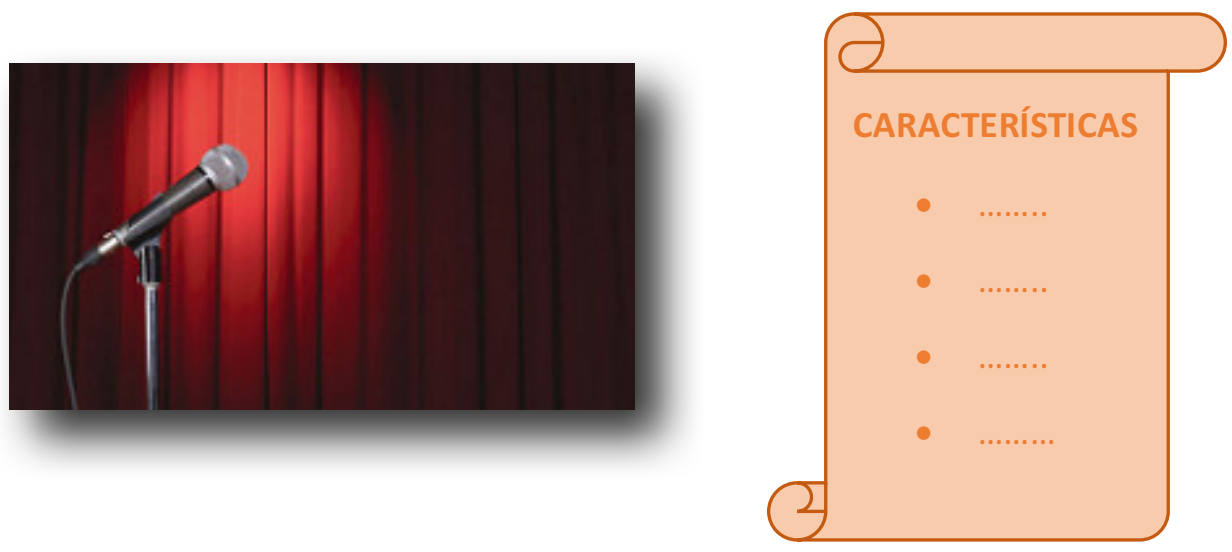

- ¿Conoces a este hombre? ¿A qué se dedica? Sólo hay una opción correcta

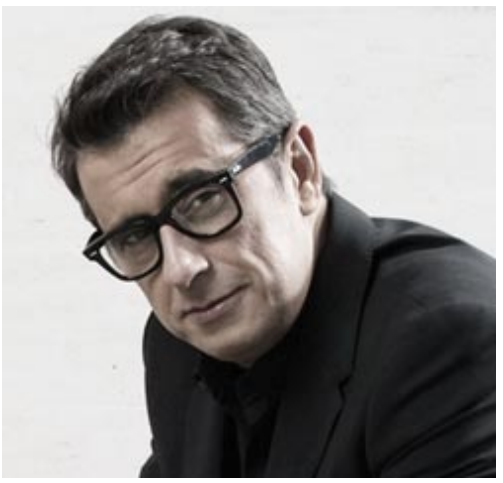
A) POLÍTICO
B) COCINERO
C) ENTRENADOR DE FÚTBOL
D) HUMORISTA

- A continuación, mira la primera escena del vídeo. ¿Dónde crees que está Andreu? ¿A quién va a dirigirse? Coméntalo con tu compañer@

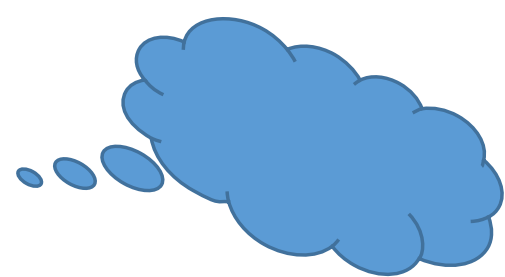




\section{ACTIVIDAD 2}

- Mira el glosario que a continuación te presentamos. ¡Te será muy útil para entender después el monólogo!

\section{GLOSARIO}

- David Broncano: Cómico y presentador de televisión español.

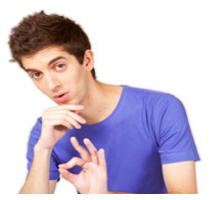

- Íñigo Errejón: Político español en la ejecutiva del partido de Podemos. (Suelen hacer chistes sobre su aspecto juvenil).

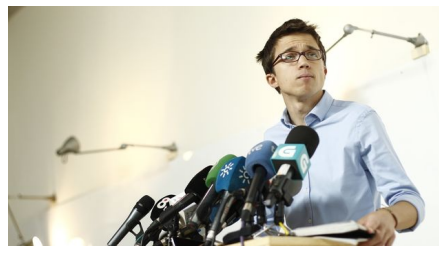

- Luís Bárcenas: Ex-político español perteneciente al partido popular, condenado por robar dinero público.

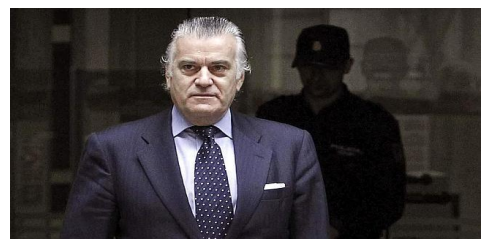

- Atesorar: reunir o guardar dinero

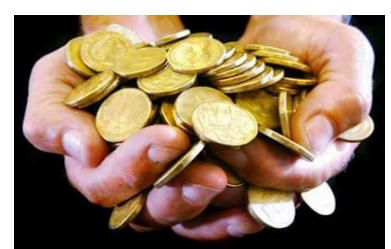

- Pokemines ¡no, gracias! Debes dejarlos crecer: Se trata de una Desautomatización del conocido eslogan publicitario de pesca marítima: Pezqueñines jno, gracias! Debes dejarlos crecer 
- Botella de butano: recipiente que contiene gas como combustible doméstico

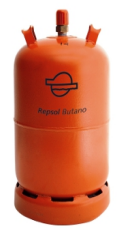

- Incubar: Hecho de calentar los huevos con su cuerpo para que nazcan las crías.

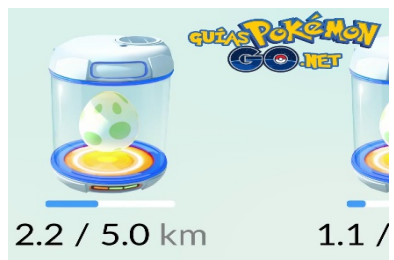

- Eclosionar: Acto de rotura del huevo para el nacimiento de un animal

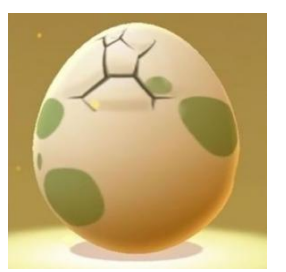

- Chungo/a: Adjetivo coloquial que describe algo difícil o complicado.

- Legendario: Adjetivo que describe algo perteneciente a una leyenda.

- ¿Crees que has entendido el monólogo? ¡Vamos a comprobarlo! Usa la tarjeta verde si crees que la afirmación es VERDADERA y la tarjeta roja si piensas que es FALSA.

El juego de Pokémon Go no engancha

La gente en lugar de comparar abdominales compara Pikachus

La gente va a las Pokeparadas a conseguir huevos

Conoceremos a nuestro futuro amor cazando Pokémons 
¡A debatir! ¿Creéis que se nos está yendo de las manos el uso del teléfono móvil? ¿Es conocido este juego en vuestro país? ¿Cómo se comporta la gente?

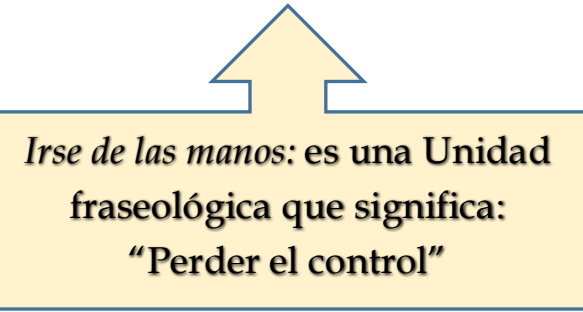

\section{ACTIVIDAD 3}

- Observa las siguientes expresiones. ¿Crees que son humorísticas?

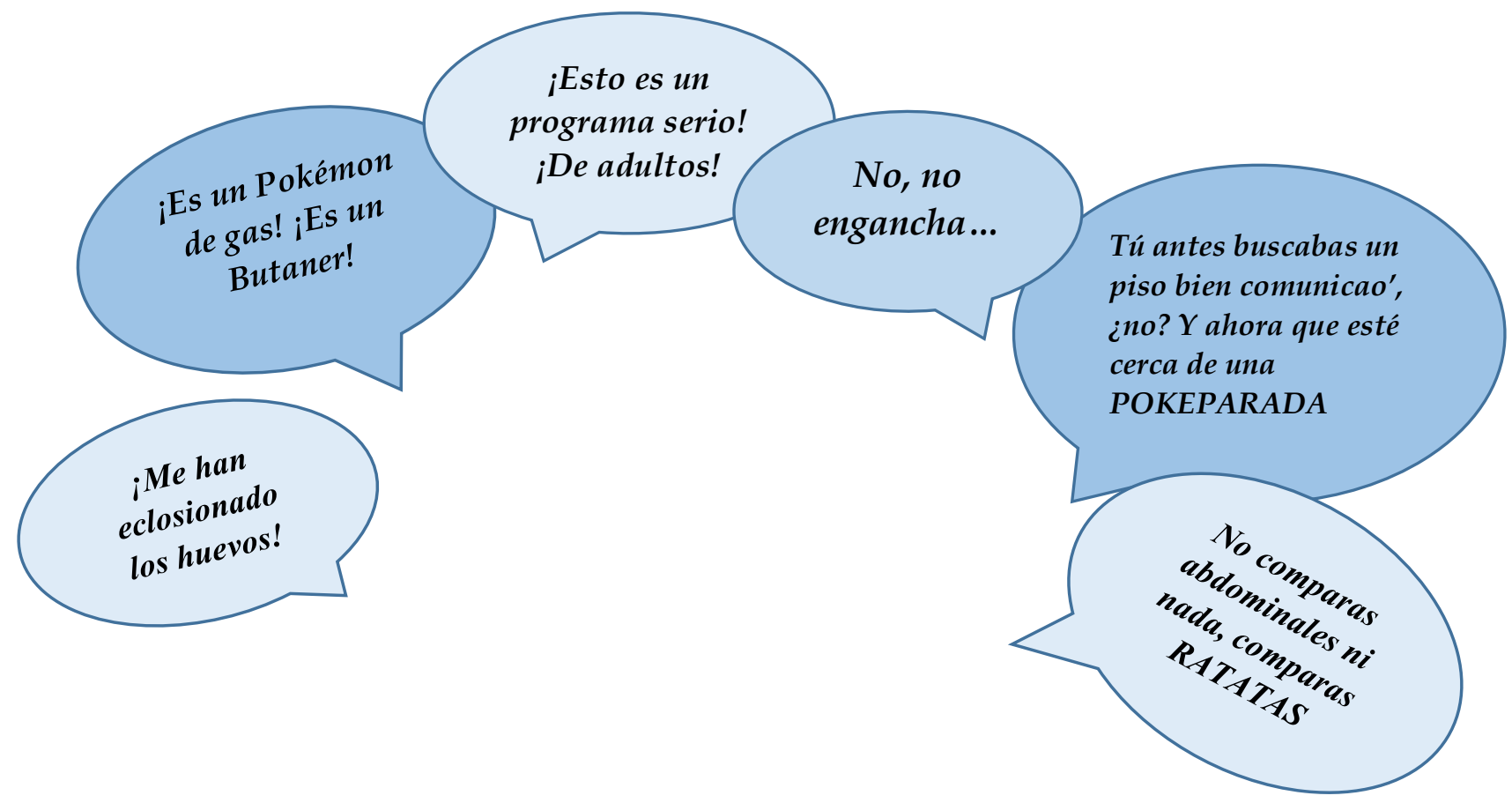

- Cada una de estas expresiones contiene una figura retórica. Vuelve a ver el monólogo e intenta averiguar de cuál se trata. Escribe cada expresión en la casilla correspondiente.

\begin{tabular}{|l|l|l|}
\hline $\begin{array}{l}\text { FIGURA } \\
\text { RETÓRICA }\end{array}$ & DEFINICIÓN & EXPRESIÓN \\
\hline Hipérbole & Exageración de la realidad & \\
\hline Paradoja & Incoherencia o contrasentido & \\
\hline
\end{tabular}

\footnotetext{
${ }^{6}$ Definiciones tomadas del Diccionario de la Real Academia Española (DRAE). Accesible en www.dle.rae.es
} 


\begin{tabular}{|l|l|l|}
\hline Antítesis & $\begin{array}{l}\text { Asociación de dos } \\
\text { pensamientos contrarios }\end{array}$ & \\
\hline Metáfora & $\begin{array}{l}\text { Traslación de las } \\
\text { características de una } \\
\text { realidad a otra }\end{array}$ & \\
\hline Símil & $\begin{array}{l}\text { Comparación, semejanza } \\
\text { entre dos cosas }\end{array}$ & \\
\hline Polisemia & Pluralidad de significados & \\
\hline
\end{tabular}

\section{ACTIVIDAD 4}

- ¡EQUIPO A contra EQUIPO B! Cada uno de los equipos tenéis una expresión común coloquial del lenguaje español con su definición. Deberéis inventaros dos definiciones más y exponer de forma convincente los tres posibles significados a vuestros rivales. ¡El objetivo es confundirlos y que no acierten el significado real a la primera!

EQUIPO A: Más vale pájaro en mano que ciento volando.

Se aplica a quiénes prefieren tener algo sencillo pero seguro que no algo mejor pero incierto

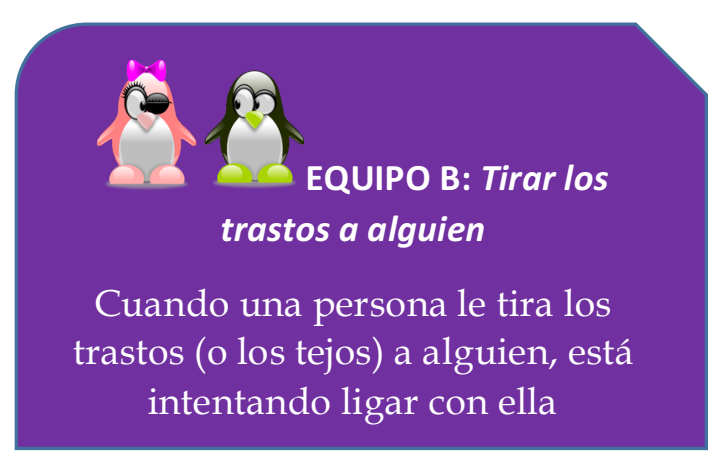

- Con la transcripción delante, vuelve a ver el vídeo e identificad unas expresiones similares que Buenafuente ha adaptado al vocabulario de Pokémon.

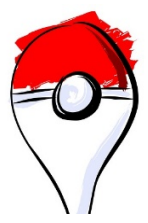

- Por último, intentad inventar vuestras propias expresiones a partir del refrán "más vale pájaro en mano que ciento volando 


\section{ACTIVIDAD 5}

- Mira estas frases... ¡Están incompletas! ¿Recuerdas cómo acaban? ¡Vamos a hacer memoria!

esto está cambiando la vida de las

personas humanas,

\section{por curiosidad,}

tú antes buscabas un piso bien comunicao',

Tú puedes incubar un huevo,

\section{Sí, sí}

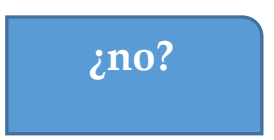

¿eh?

\section{¿eh?}

- ¿Por qué crees que Buenafuente usa estas marcas?

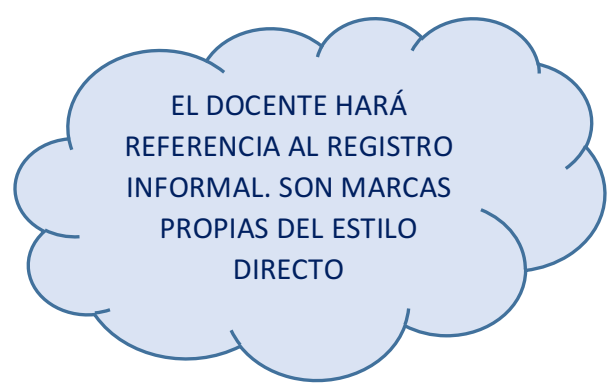

- ¡Vamos a pensar! ¿Cuáles son las funciones del humor en español? Deberéis aportar ideas en la pizarra y así crear, entre todos, una infografía. 


\section{- LAS FUNCIONES DEL HUMOR}

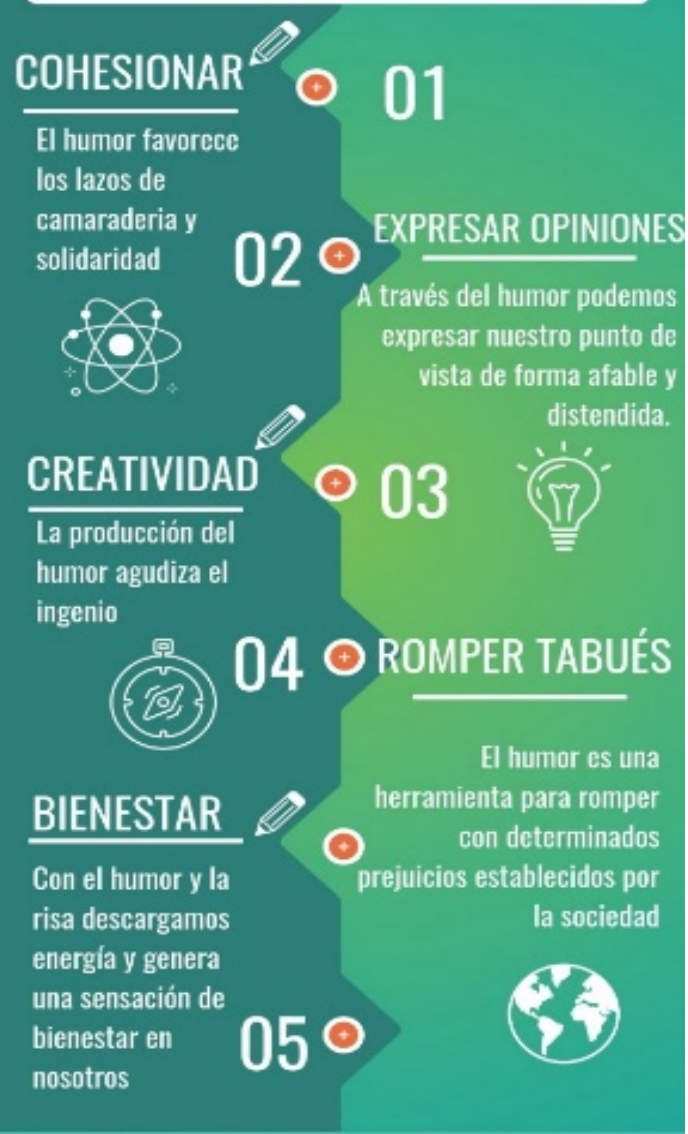

\section{ACTIVIDAD 6}

- ¿Creéis que el humor es diferente en cada país o hay rasgos similares? ¡Vamos a hablar!

TRUCOS: Para ganar tiempo para pensar (usando marcadores $\mathbf{m m m}$, eeeh, déjame ver...). Para cambiar de tema (a propósito, fijate, por otro lado...)

Para dar tu opinión: creo que..., Yo no estoy de acuerdo..., Pues a mi me parece que... 